\title{
Spreading depression and interhemispheric transfer of an avoidance response'
}

\author{
FRANK A. BEACH, III \\ SAN FRANCISCO STATE COLLEGE
}

By the use of spreading cortical depression, an avoidance response was established in a single hemisphere in 10 rats. The interhemispheric transfer of this response could be demonstrated in $50 \%$ of the Ss following a single conditioning trial with both cortical hemispheres functional. Transfer of the response was not dependent upon the $S$ receiving shock during this 1 trial.

Recently, several investigators (Russell \& Ochs, 1963; Ray \& Emley, 1964) have employed the phenomenon of spreading cortical depression to produce a functional split-brain animal for the study of interhemispheric transfer of unilateral learning. Their results indicate that it is possible to establish a CR based on appetitive drive in a single hemisphere of such an animal. Furthermore, a single reinforced trial, with both hemispheres functional, is sufficient for the transfer of the unilaterally established $C R$. The present experiment is designed to test the hypothesis that the 1-trial transfer phenomenon is applicable to avoidance learning, and more specifically to determine whether the primary motivator (shock) is necessary for the transfer.

\section{Method and Procedure}

The Ss were eight female and four male rats from the Berkeley $\mathrm{K}$ strain, ranging in age from 95 to 125 days old.

The apparatus was a shuttlebox separated into two equal-sized compartments, $18 \times 5$ in., by a hurdle, 2 in. high, and a guillotine door. One compartment was white on three sides and the other black, with the front being glass to allow for observation. The floor of the entire box was formed by an electric grid.

The CS was a 25 watt light located near the ceiling of the black compartment, the shock side throughout the experiment. The UCS was a 60 cycle AC current of approximately .5 ma delivered to the grid of the black compartment from a constant source. The shock was controlled by the experimenter and was interrupted approximately twice per second. Both CS and UCS were terminated by hand switches operated by the experimenter when the $S$ had crossed all $4 \mathrm{ft}$. into the white or safe compartment.

Forty-eight hr. prior to their first training Ss were prepared surgically. Trephine holes $3 \mathrm{~mm}$ in diameter were drilled bilaterally between the lambda and the bregma, approximately $2 \mathrm{~mm}$ lateral to the median plane, exposing the parieto-occipital brain surfaces of both hemispheres. Care was taken in drilling not to rupture the dura.

Stainless steel tubes $1 \mathrm{~cm}$ long were fitted into the trephine holes. The tubes were held by dental cement which adhered to the bone and to dental screw-posts which were fixed to the skull surface. Rubber caps were fitted over the tubes to avoid exposure of the dura to air and as a protection against foreign matter. Throughout the experiment the tubes were flushed daily with physiological saline. Following the operation, the Ss remained in their home cages for a minimum recovery period of $48 \mathrm{hr}$.

Prior to each day's avoidance trials, the Ss' tubes were flushed with saline and a drop of $10 \% \mathrm{KCl}$ was injected into one of the tubes by means of a hypodermic needle cut to a length of $1 \mathrm{~cm}$. Half of the $\mathrm{Ss}$ received treatment to the right hemisphere and half to the left throughout the entire avoidance training. One hr. after completion of the day's trials the tubes were again flushed with saline. After application of $\mathrm{KCl}$, Ss were placed in their home cages for $15 \mathrm{~min}$. prior to their training trials. Throughout the experiment the black compartment was the shock side and the white the safe side. The CS-UCS interval was $5 \mathrm{sec}$, and the intertrial interval, during which the S remained in the white compartment, was $30 \mathrm{sec}$. During avoidance training Ss that did not escape the shock within 240 sec. were removed and placed in the white compartment for the intertrial interval. The avoidance training was conducted in daily sessions of $30 \mathrm{~min}$. per $S$ until a criterion of 9 out of 10 consecutive successful avoidance trials was recorded. All Ss reached criterion within 45 trials.

The experiment was divided into five identical phases for all Ss. The last five trials of avoidance training, during which the Ss reached criterion, constituted Phase I.

In Phase II, on the day following criterion, the Ss were tested to determine if unilateral learning had taken place. For this test, the "learned" hemisphere that had been untreated during avoidance training was depressed with $\mathrm{KCl}$ and the contralateral "naive" side was not treated. This phase consisted of five extinction trials with $10 \mathrm{sec}$. of CS but no UCS. If the S did not cross to the white compartment within this time he was removed and placed there for the intertrial interval. The latencies of these trials were compared with those of Phase I to determine if unilateral learning had taken place.

In Phase III, on the day following Phase II, all Ss were given a single trial with no $\mathrm{KCl}$ administered. On this trial, as in Phase I, Ss which did not avoid within 5 sec. were subject to shock.

Phase IV followed the single trial by $1 \mathrm{hr}$., and was a replication of Phase II. That is, $\mathrm{KCl}$ was injected into the tube on the "learned" side and the "naive" hemisphere was left untreated for five extinction trials. The latencies 
of these trials were then compared to those for Phase I and Phase II to determine if the learning had transferred during the single trial of Phase III. Phase III, the single trial, was the only experimental event separating the two identical tests of the "naive" hemisphere, Phase II and Phase IV.

Phase $\mathrm{V}$, following $1 \mathrm{hr}$. after Phase IV, consisted of five extinction trials with $\mathrm{KCl}$ applied to both hemispheres.

\section{Results and Discussion}

Results are presented here for $10 \mathrm{Ss}$, all of which showed evidence of unilateral learning. Of the two Ss discarded, one failed to show unilateral learning and the other suffered damage to the skull cap preparation.

To determine the occurrence of transfer, a Rank Sum Test for the difference between two medians was applied to the latencies of Phase I and Phase IV and transfer was found to have occurred in 5 of the $10 \mathrm{Ss}$. The occurrence of transfer, or lack of it, was strikingly obvious in each case. Of the Ss showing transfer, none received shock more than once during the five extinction trials of Phase IV, while of the remaining Ss, none avoided the shock more than once during this phase. Because of this fact, the data is separated into two groups designated transfer Ss and non-transfer Ss.

For the five Ss giving evidence of transfer, the difference between Phase I and Phase II, as well as the difference between Phase IV and Phase $\mathrm{II}_{0}$ is significant beyond the .05 level. Also, both Phase I and Phase IV are significantly different from Phase V. The difference between Phase I and Phase IV is, of course, not significant.

For the five Ss which did not show transfer, there were no significant differences between Phase II, Phase IV and Phase V. All of these latencies were significantly different from Phase I.

In order to establish a baseline for operant crossing from one compartment to the other, a group of un-

Table 1. Mean group latencies measured in seconds.

\begin{tabular}{lrrrrr} 
& Phose I Phase II Phase III Phase IV Phase V \\
\hline Transfer Ss & 2.7 & 9.1 & 11.6 & 4.2 & 7.2 \\
Non-transfer Ss & 2.1 & 8.4 & 8.4 & 7.8 & 8.9 \\
\hline
\end{tabular}

operated controls was run. The mean latency for the controls, $8.0 \mathrm{sec}$., is comparable to the experimental Ss in test Phases II, IV and V, with the exception of Phase IV where the transfer Ss showed evidence of their previous avoidance training. This indicates that naivete, rather than a side effect of the $\mathrm{KCl}$ is responsible for the long latencies in these phases.

The results obtained in the present experiment are in accord with a number of investigators who have reported the successful use of spreading depression as a means of unilateral learning. The results further indicate that the 1-trial transfer phenomenon, reported in connection with CRs based on an appetitive drive, also occurs with an avoidance CR. Although only $50 \%$ of the Ss in the present experiment showed this transfer, their performance was significantly different from the Ss not demonstrating transfer and from the controls.

Russell and Ochs presented evidence that transfer does not occur for Ss who do not receive primary reinforcement during their 1-trial experience. In the present study two of the five Ss that demonstrated transfer did not receive shock during their 1 -trial experience, Phase III. Therefore, although shock was necessary to establish the CR, it was not a necessary condition for transfer to the contralateral hemisphere. It is possible that a number of clues in the black compartment serve as a CS evoking a generalized fear reaction, and that crossing to the white compartment affords a measure of relief from the fear. Using this interpretation, borrowed from the theoretical ideas of Mowrer, it would not be essential for the $S$ to receive shock during Phase III, as relief from the conditioned fear would be considered a primary reinforcer.

\section{References}

Ray, O. S., \& Emley, G. Time factors in interhemispheric transfer of learning. Science, 1964, 144, 76-78.

Russell, I. S., \& Ochs, S. Localization of a memory trace in one cortical hemisphere and transfer to the other. Brain, 1963,86, 37-54.

\section{Notes}

1. The research reported here is from a thesis submitted to the Graduate School of San Francisco State College in partial fulfillment of degree of Master of Arts.

2. Now at University of Colorado. 